\title{
ER-Mitochondria Contacts and Insulin Resistance Modulation through Exercise Intervention
}

\author{
Yi Sun ${ }^{1,2}$ and Shuzhe Ding ${ }^{1,2, *}$ \\ 1 Key Laboratory of Adolescent Health Assessment and Exercise Intervention of Ministry of Education, \\ East China Normal University, Shanghai 200241, China; ysun@tyxx.ecnu.edu.cn \\ 2 College of Physical Education and Health, East China Normal University, Shanghai 200241, China \\ * Correspondence: szding@tyxx.ecnu.edu.cn
}

Received: 14 November 2020; Accepted: 14 December 2020; Published: 16 December 2020

\begin{abstract}
The endoplasmic reticulum (ER) makes physical contacts with mitochondria at specific sites, and the hubs between the two organelles are called mitochondria-associated ER membranes (MAMs). MAMs are known to play key roles in biological processes, such as intracellular $\mathrm{Ca}^{2+}$ regulation, lipid trafficking, and metabolism, as well as cell death, etc. Studies demonstrated that dysregulation of MAMs significantly contributed to insulin resistance. Alterations of MAMs' juxtaposition and integrity, impaired expressions of insulin signaling molecules, disruption of $\mathrm{Ca}^{2+}$ homeostasis, and compromised metabolic flexibility are all actively involved in the above processes. In addition, exercise training is considered as an effective stimulus to ameliorate insulin resistance. Although the underlying mechanisms for exercise-induced improvement in insulin resistance are not fully understood, MAMs may be critical for the beneficial effects of exercise.
\end{abstract}

Keywords: MAMs; insulin resistance; exercise; obesity; diabetes

\section{Introduction}

Recent studies have shown that cellular organelles perform proper functions by interacting with other organelles. Mitochondria are dynamic organelles that play a key role in energy conversion. Mitochondria exhibit structural and functional diversity, and subsets of mitochondria form physical contacts with other types of organelles, including the endoplasmic reticulum (ER) [1], peroxisomes [2], lipid droplets [3], etc. The ER is the main site for the synthesis of proteins and lipids, membrane biogenesis, xenobiotic detoxification, and cellular $\mathrm{Ca}^{2+}$ storage. Proper functions of the mitochondria and ER are essential for maintaining cellular homeostasis. In addition to playing distinct cellular roles, the mitochondria and ER form physical interactions at specific sites, which are called mitochondria-associated ER membranes (MAMs). This unique structure serves as the platform for communication between the two organelles, and is critical for $\mathrm{Ca}^{2+}$ crosstalk, lipid transport, energy metabolism, ER redox control, mitochondria dynamics, cell survival, inflammation, etc. [4].

Accumulating evidence has suggested that alterations of the structure and function of MAMs are closely associated with numerous diseases, such as diabetes mellitus [5], metabolic syndrome [6], nonalcoholic fatty liver disease (NAFLD) [7], cancer [8], and neurodegenerative diseases [9,10]. However, the specific role of MAMs in insulin resistance is still elusive. Moreover, it remains unclear whether the alleviation of insulin resistance by exercise intervention involves the participation of MAMs. Therefore, the aim of this review is to summarize the current understanding of the structure and functions of MAMs, the association between dysfunctional MAMs and insulin resistance, and the current progress on exercise interventions for MAMs modification and insulin resistance improvement. 


\section{The Structure of MAMs}

The physical interactions between the mitochondria and ER depend on complementary membrane proteins that tether the two organelles at specific sites. Several crucial proteins act as tethers between the mitochondria and ER, including PACS-2 (phosphofurin acidic cluster sorting protein 2) [11], Mfn2 (mitofusin 2)-Mfn1/2 [12], IP3R (inositol 1, 4, 5-triphosphate receptor)- Grp75 (glucose regulated protein 75)-VDAC (voltage-dependent anion channel) complex, Fis1-Bap31 [13], VAPB (vesicle-associated membrane-protein-associated protein B)-PTPIP51 (protein tyrosine phosphatase-interacting protein 51) [14], and MOSPD2-PTPIP51 [15] (Figure 1). Some other regulatory proteins are also enriched at MAMs, including calnexin (CNX) [16], sarco/ER $\mathrm{Ca}^{2+}$ ATPase (SERCA), sigma-1 receptor (Sig1R) [17], endoplasmic reticulum oxidoreductin-1 $\alpha$ (Ero1 $\alpha)$ [18], ACSL4/FACL4 [19], phosphatidylserine synthase (PSS) [20], Atg14 [21], CypD (cyclophilin D) [22], Akt [23], mTORC2 (mammalian TOR complex 2), etc. Mitochondria are closely associated with both rough ER and smooth ER. Tethers connecting the OMM (outer mitochondrial membrane) and smooth ER have measured lengths of 9-16 nm, and are measured at 19-30 nm between the OMM and rough ER [24]. In addition, the interaction between mitochondria and ER accounts for about $20 \%$ of the total mitochondrial network [25]. In mammalian skeletal muscle, tight coupling is observed between the sarcoplasmic reticulum (SR) and mitochondria. The close interaction between the SR and mitochondria forms bidirectional signaling between the two organelles, which are called "orthograde" (SR to mitochondria) communication and "retrograde" (mitochondria to SR) communication [26]. $\mathrm{Ca}^{2+}$ signaling, metabolic processes, muscle fatigue, and muscle damage during exercise are all impacted by SR-mitochondria coupling.

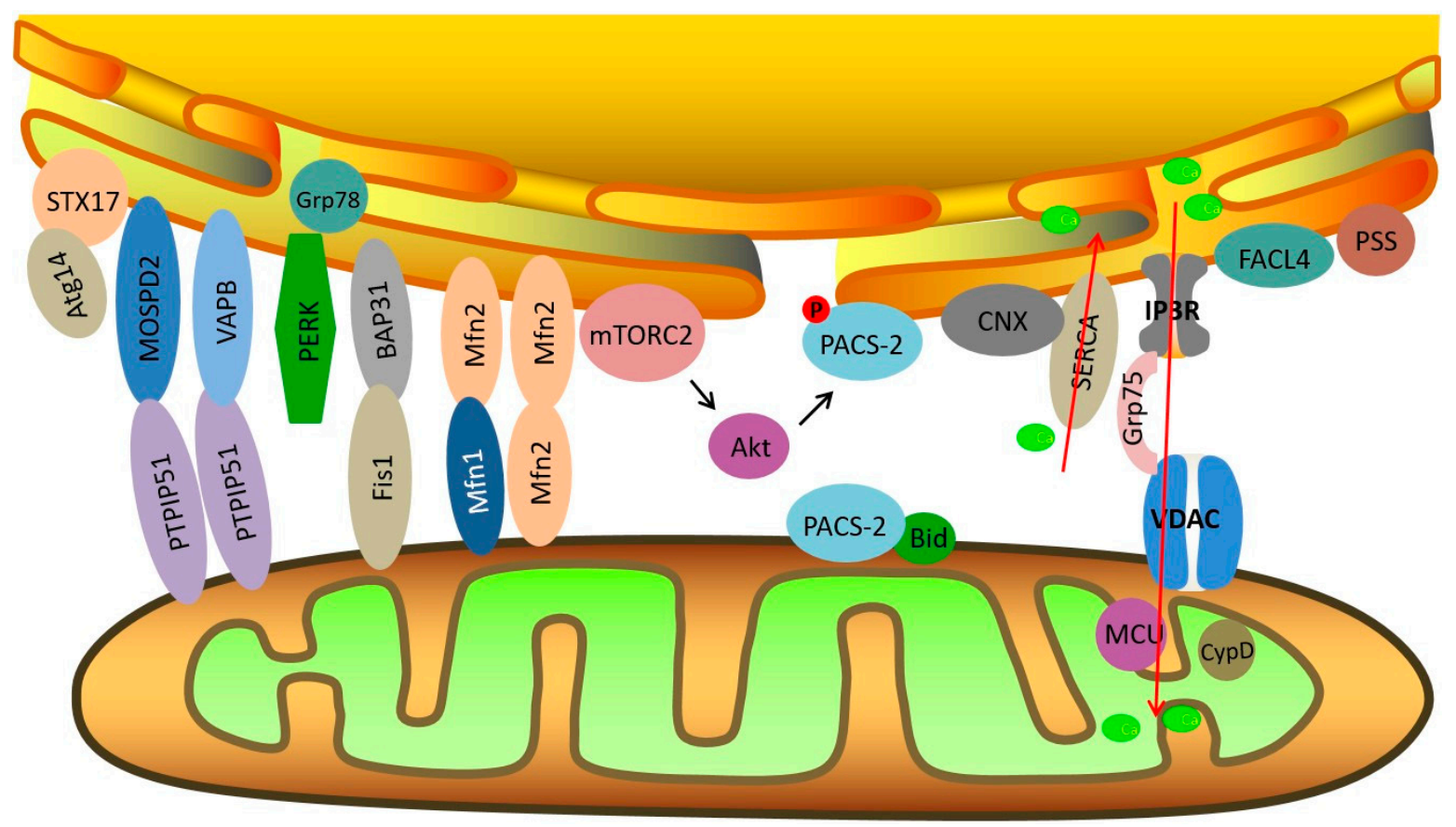

Figure 1. Schematic diagram of endoplasmic reticulum (ER)-mitochondria contact sites and key molecules related to insulin signaling at mitochondria-associated ER membranes (MAMs). Red arrows signify the direction of $\mathrm{Ca}^{2+}$ transport.

The key molecules and tethers located at MAMs that are associated with insulin sensitivity maintenance are briefly reviewed below. 


\subsection{The IP3R-Grp75-VDAC Complex}

$\mathrm{Ca}^{2+}$ is an essential second messenger. Intracellular $\mathrm{Ca}^{2+}$ homeostasis is maintained partly through $\mathrm{Ca}^{2+}$ transfer from the ER to the mitochondria. The VDAC of the outer mitochondrial membrane interacts with IP3R on the ER through the molecular chaperone Grp75, which is a cytosolic Hsp70. This complex allows mouth-to-mouth $\mathrm{Ca}^{2+}$ transfer from the ER to the mitochondria [27]. Evidence suggested that deficiency in Grp75 caused a decrease in ER-mitochondria $\mathrm{Ca}^{2+}$ exchange [28]. However, excessive entrance of $\mathrm{Ca}^{2+}$ into mitochondria would lead to mitochondrial $\mathrm{Ca}^{2+}$ overload, triggering apoptosis.

\section{2. $M f n 2$}

Mfn2, a ubiquitously expressed mitochondrial transmembrane dynamin-like GTPase protein, plays a fundamental role in mitochondrial fusion. Mfn2 was discovered as a direct ER-mitochondria tether, regulating the interactions as well as $\mathrm{Ca}^{2+}$ transfer between ER and mitochondria [29]. Ablation of Mfn2 caused fragmentation of the ER, impaired mitochondrial $\mathrm{Ca}^{2+}$ uptake, and increased distance between the two organelles [29]. Several molecules, such as trichoplein/mitostatin (TpMs) [30] and MITOL [31], impact ER-mitochondria tethering via interacting with Mfn2.

\section{3. $C y p D$}

CypD is a member of the cyclophilin family, and is located in the mitochondrial matrix. It is important for regulating mitochondrial function and controlling the mitochondrial permeability transition pore (mPTP). To date, the exact role of CypD in regulating mitochondrial function still remains elusive. It is suggested that CypD interacts with the IP3R-Grp75-VDAC1 $\mathrm{Ca}^{2+}$-channeling complex at the MAMs' interface [22]. CypD is crucial for maintaining MAMs integrity through an unknown mechanism, revealed by the fact that significant reduction of MAMs amount was observed in the liver of CypD-KO mice [23].

\subsection{PACS-2}

PACS-2 is expressed in the skeletal muscles, heart, brain, and liver, and is involved in various cellular processes, such as membrane trafficking, apoptosis, and autophagy [11]. Confocal microscopy confirmed that PACS-2 was located at MAMs [32]. PACS-2 is essential for the maintenance of MAMs integrity. Depletion of PACS-2 caused mitochondria fragmentation, which uncoupled from the ER [32]. MAMs integrity was also affected by phosphorylation of PACS-2 mediated by mTORC2-Akt signaling [33].

\section{The Main Functions of MAMs}

\subsection{Lipid Exchange}

Most lipids are synthesized in the ER and transported to mitochondria. Therefore, MAMs are crucial for lipid synthesis and trafficking. MAMs contain numerous phospholipid- and glycosphingolipid-synthesizing enzymes, and support the direct transfer of phospholipids from the ER to mitochondria [34].

FACL4 and PSS-1 are both MAMs-localized proteins. FACL4 is the enzyme that converts fatty acids into fatty acyl-CoA esters, and PSS-1 catalyzes the reaction where the polar head group of PE (phosphatidylethanolamine) or PC (phosphatidylcholine) is replaced by L-serine. Knockdown of either PACS-2 or Mfn2 caused a reduced level of MAMs-associated FACL4 and PSS-1 [32,35].

\section{2. $\mathrm{Ca}^{2+}$ Homeostasis}

$\mathrm{Ca}^{2+}$ functions as an important second messenger, and plays a key role in regulating various protein kinases and transcription factors, influencing their expressions or activities. Disruption of 
$\mathrm{Ca}^{2+}$ homeostasis is closely related to several pathologies and chronic diseases, such as cardiac diseases, Alzheimer's disease, diabetes, etc. [36]. The majority of $\mathrm{Ca}^{2+}$ transportation between mitochondria and ER is performed through MAMs. Mitochondria take up $\mathrm{Ca}^{2+}$ following an increase in cytosolic $\mathrm{Ca}^{2+}$. In addition to modulating cytosolic $\mathrm{Ca}^{2+}$ transient, mitochondrial uptake of $\mathrm{Ca}^{2+}$ activates key enzymes of the Krebs cycle, thereby regulating mitochondrial ATP production. Therefore, MAMs effectively integrate $\mathrm{Ca}^{2+}$ flux with cellular metabolic pathways. However, excessive $\mathrm{Ca}^{2+}$ entrance into mitochondria induces the opening of $\mathrm{MPTP}$ and release of pro-apoptotic factors, causing detrimental effects on cell viability [37].

The $\mathrm{Ca}^{2+}$ level in the cytosol is in the nanomolar range, compared to the millimolar range in the ER [38]. The huge discrepancy is generated by both SERCA, which pumps $\mathrm{Ca}^{2+}$ into the ER, and by plasma membrane $\mathrm{Ca}^{2+}$ ATPases (PMCA), which pump $\mathrm{Ca}^{2+}$ out of the cell [28]. $\mathrm{Ca}^{2+}$ transfer from the ER to mitochondria is regulated by the IP3R-Grp75-VDAC1-MCU axis [39]. When ryanodine receptor (RyR) and IP3R-both of which are ER Ca ${ }^{2+}$ channels-open, a transient increase in cytosolic $\mathrm{Ca}^{2+}$ level occurs, activating downstream $\mathrm{Ca}^{2+}$-binding proteins. Mitochondrial $\mathrm{Ca}^{2+}$ uniporter (MCU) is the major regulator of mitochondrial $\mathrm{Ca}^{2+}$ uptake. Microdomains of high $\left[\mathrm{Ca}^{2+}\right]$ are created at the MAMs to facilitate rapid $\mathrm{Ca}^{2+}$ uptake via the MCU complex.

The $\mathrm{Ca}^{2+}$ crosstalk between the ER and mitochondria is regulated by several factors. For example, CNX interacts with SERCA to regulate intracellular $\mathrm{Ca}^{2+}$ oscillations [40]. In addition, PACS-2 is required for oxidized LDL-induced mitochondrial $\mathrm{Ca}^{2+}$ elevation, cell apoptosis, and MAMs formation [41]. In addition, knockdown of polycystin 2 (PC2) increased the expression of Mfn2, enhanced the tethering between mitochondria and ER, and caused an increase in mitochondrial $\mathrm{Ca}^{2+}$ entry [42].

$\mathrm{Ca}^{2+}$ also plays an essential role in the regulation of cell death. When mitochondria and ER are aberrantly closely apposed, the mitochondria matrix is overloaded by $\mathrm{Ca}^{2+}$, causing the opening of $\mathrm{mPTP}$ and release of cytochrome $\mathrm{c}$ as well as other apoptotic stimuli [43].

\subsection{Apoptosis}

Mitochondrial $\mathrm{Ca}^{2+}$ overload is a trigger to stimulate apoptosis. Therefore, prolonged and over-tightened connections between the ER and mitochondria can be converted into apoptotic stimuli [1]. On the other hand, Fis1 and Bap31 bridge mitochondria and the ER by physically interacting with each other. The tripartite protein complex composed of procaspase-8, Bap31, and Fis1 transmits an apoptotic signal from mitochondria to the ER. The interesting part is that instead of directly inducing mitochondrial fission, Fis1 actually interacts with Bap31 to modulate the release of $\mathrm{Ca}^{2+}$ from the ER, which then affects mitochondrial fission and apoptosis [13].

\subsection{Autophagy}

Macroautophagy is a conserved process by which cells engulf cytoplasmic contents and organelles and fuse with lysosomes for degradation [1]. The origin of the isolation membrane for formation of autophagosomes has been under debate for years. Recent studies suggested that MAMs were the key platform for autophagosome formation [35]. As a pre-autophagosome/autophagosome marker, Atg14 relocated exclusively to MAMs upon starvation [35]. In addition, as the marker of autophagosome formation, the majority of Atg5 was observed at the ER-mitochondria contact site during the entire autophagosome formation process [35]. On the other hand, disruption of MAMs structure also interfered with the autophagic process, revealed by the observation that knockdown of PACS-2 or Mfn2 caused a decrease in Atg14 and LC3II [35]. However, there was also opposing evidence that suggested that tightening the ER-mitochondria connection might actually impair autophagy. For example, overexpression of VAPB (ER protein) and RMDN3 (protein on the outer mitochondrial membrane) tightened ER-mitochondria contacts and inhibited chemical-induced autophagosome formation [44]. Similarly, strengthening VAPB-PTPIP51 tethers to tighten ER-mitochondria contacts also impaired autophagosome formation [14]. Further research suggested that MAMs-mediated 
autophagy impairment involved enhanced $\mathrm{Ca}^{2+}$ uptake by mitochondria, and could be rescued by blocking $\mathrm{Ca}^{2+}$ exchange between the ER and mitochondria [14,44].

\section{Dysfunction of MAMs and Insulin Resistance}

Insulin resistance is the state in which responses of peripheral target tissues, including skeletal muscle, adipose tissue, and liver, to the physiological level of insulin are reduced [45]. Since the mitochondria and ER are both essential for maintaining metabolic homeostasis, it is not surprising that impaired functions of the mitochondria, ER, and MAMs are associated with metabolic disturbances such as obesity, insulin resistance, metabolic syndrome, etc. Among the above metabolic disturbances, obesity is closely related to the development of insulin resistance, while insulin resistance plays an essential role during the initiation and progression of metabolic syndrome [11].

\subsection{MAMs and Insulin Signaling}

\subsubsection{MAMs Juxtaposition and Integrity}

Several imaging techniques have been used to assess the interactions of the mitochondria and $\mathrm{ER}$, including transmission electronic microscopy, electron tomography [46], immunocolocalization of mitochondria- and ER- specific fluorescent proteins [25], and in situ proximity ligation assay (PLA) [23]. Of the above-mentioned techniques, in situ PLA allows for visualization and quantification of interactions between VDAC-IP3R or Grp75-IP3R [47,48]. However, to date, there is no consensus of whether organelles' juxtaposition is increased or decreased in models of insulin resistance. Some studies reported that obesity caused an abnormal increase in MAMs formation, which resulted in an increased $\mathrm{Ca}^{2+}$ flux from the ER to mitochondria in the liver of mice [49]. Others found that a reduction of ER-mitochondria interactions was associated with metabolic alterations in the liver of both ob/ob and diet-induced insulin-resistant mice [23]. Insulin resistance in the skeletal muscle has also been proved to be related to disruption of MAMs. A marked decrease in SR/ER-mitochondria interactions (also called MAMs for convenience) and mitochondrial dysfunction were observed in the skeletal muscle of diet-induced obese mice [50]. In addition, MAMs juxtaposition is also affected by nutritional state. ER-mitochondria proximity, which was examined by transmission electron microscopy (TEM) analysis, was reduced in the liver of fed mice compared with fasted mice [51].

Some evidence has suggested that MAMs integrity is required for maintaining insulin sensitivity. For example, it has been found that genetic or pharmacological inhibition of CypD disrupted MAMs integrity and impaired insulin signaling in primary hepatocytes [23]. Conversely, overexpression of CypD increased organelle contacts and enhanced insulin action in primary hepatocytes of diabetic mice. In addition, treatment of $C y p D K O$ mice with metformin improved both MAMs integrity and insulin sensitivity [23]. A similar role of Mfn2 in maintaining MAMs integrity and insulin sensitivity was also observed. For example, liver-specific Mfn2 KO mice showed glucose intolerance, enhanced hepatic gluconeogenesis, and impaired response to insulin [12]. Conversely, overexpression of Mfn2 improved high-fat diet (HFD)-induced hepatic insulin resistance in rats [52]. Moreover, ER-mitochondria contacts in POMC neurons of the hypothalamus were decreased in diet-induced obesity. Deletion of Mfn2 in POMC neurons disrupted proper mitochondrial-ER homeostasis, and led to reduced energy expenditure, leptin resistance, and obesity [53]. The impact of MAMs integrity maintenance on insulin sensitivity in the adipocytes has also been investigated. Cisd2 is a causative gene associated with Wolfram syndrome. Cisd2 and GTPase of immune-associated protein 5 (Giamp5) were found to interact with each other at MAMs and to regulate intracellular $\mathrm{Ca}^{2+}$ homeostasis by promoting mitochondrial $\mathrm{Ca}^{2+}$ uptake [54]. It was noticed that a deficiency in Cisd2 caused elevation in the cytosolic $\mathrm{Ca}^{2+}$ level, activating $\mathrm{Ca}^{2+}$-calcineurin-dependent pathway and downregulating genes related to mitochondrial biogenesis. Therefore, mitochondrial dysfunction and impaired insulin sensitivity in adipocytes were observed [54]. Even though the above evidence supported the positive role of MAMs integrity in maintaining systemic and tissue insulin sensitivity, opposite observations were also seen with regard to 
PACS-2. A study demonstrated that knockdown of PACS-2, the protein essential for ER-mitochondria tethering, improved insulin sensitivity in the obese mice [49]. Therefore, it seems that proper MAMs juxtaposition and integrity are required in order to maintain insulin sensitivity. ER-mitochondria contact that is tighter than normal would cause mitochondrial $\mathrm{Ca}^{2+}$ overload, trigger cellular apoptosis, and inhibit autophagy. Conversely, loss of ER-mitochondria tethers impairs normal exchange of lipids and $\mathrm{Ca}^{2+}$ between the ER and mitochondria, thus disturbing hepatic and muscle insulin action [48].

\subsubsection{Insulin Signaling Molecules at MAMs}

In the normal conditions, the action of insulin is achieved by interacting with insulin receptors (IRs) on the cell surface. The binding of insulin to the $\alpha$ subunit of an IR causes activation of the $\beta$ subunit and, therefore, tyrosine-phosphorylating insulin receptor substrates (IRSs). IRSs then interact with and activate PI3K, causing translocation of GLUT4 to the plasma membrane.

Perturbations of ER-mitochondria interactions either genetically or pharmacologically affect insulin action. For example, silencing of Grp75 or Mfn2 decreased insulin-stimulated phosphorylation of IRS2, Akt (PKB), and GSK3 $\beta$ [23]. In addition, pharmacological inhibition of IP3R also reduced insulin-stimulated Akt phosphorylation [23]. Akt, as an important signaling protein mediating the effect of insulin, was found to be recruited at the MAMs interface and phosphorylated on Ser473 in response to insulin. The in situ PLA technique confirmed interactions between Akt and IP3R1 as well as between p-Akt-IP3R1in hepatocytes [23]. Therefore, it seems that there are different pools of Akt in hepatocytes. MAMs-located Akt expression is altered under insulin resistance. Diabetic mice were characterized by increased phosphorylated Akt in MAMs [23]. Another MAMs-residing protein, mTORC2, was known to participate in mitochondrial metabolism, cell survival, and insulin signaling [33]. To be more specific, mTORC2 controlled insulin signaling by regulating Akt activation [33] and IRS-1 level [55]. Nitric oxide (NO) generated by eNOS has been shown to regulate the insulin signaling pathway in the liver. In addition, NO regulates mitochondrial fusion and mitochondrial biogenesis through the sGC/PKG (soluble guanylate cyclase/protein kinase G) pathway [56,57]. A recent study suggested that increasing NO concentration increased MAMs and improved insulin signaling through the sGC/PKG pathway, both in vivo and in vitro [58]. In addition, disrupting MAMs significantly blunted the effects of NO on MAMs and insulin response [58].

\section{2. $\mathrm{Ca}^{2+}$ Homeostasis and Insulin Resistance}

$\mathrm{Ca}^{2+}$ homeostasis is essential for cellular metabolism, and a variety of enzymes are activated upon elevation of intracellular $\left[\mathrm{Ca}^{2+}\right]$. The mitochondria and ER are two important organelles in $\mathrm{Ca}^{2+}$ regulation. In addition to playing distinct roles in cellular processes, the mitochondria and ER also interact physically and functionally to regulate $\mathrm{Ca}^{2+}$ homeostasis [59].

Mitochondrial dysfunction and chronic activation of ER stress (ERS) are essential components in the development of insulin resistance and diabetes. Mitochondrial dysfunction triggers ERS response, which increases cellular steady-state $\mathrm{Ca}^{2+}$ levels and facilitates p38 MAPK activation, thereby leading to hepatic insulin resistance and augmented gluconeogenesis [59]. A rise in the PC/PE ratio of ER inhibited SERCA function and $\mathrm{Ca}^{2+}$ transport activity, causing hepatic ERS and aberrant glucose metabolism. Conversely, overexpression of SERCA in the liver of ob/ob mice improved $\mathrm{Ca}^{2+}$ homeostasis and glucose tolerance [60].

The level of $\mathrm{Ca}^{2+}$ in different compartments of cells must be tightly regulated in order to maintain physiological homeostasis. When transport of $\mathrm{Ca}^{2+}$ from the ER to mitochondria is enhanced due to increased MAMs formation, mitochondrial $\mathrm{Ca}^{2+}$ overload and mitochondrial dysfunction are caused, as observed in the liver of obese mice [49]. To the contrary, knockdown of IP3R1 impaired Ca ${ }^{2+}$ release from the ER and profoundly improved insulin sensitivity in obese mice [49]. IP3R activity is also impacted by insulin signaling molecules. For example, Akt was reported to phosphorylate the IP3R channel, reducing its IP3-dependent $\mathrm{Ca}^{2+}$ release capacity [61]. As a mitochondrial enzyme that is abundantly expressed in the heart and skeletal muscle, PDK4 (pyruvate dehydrogenase 
kinase 4) is significantly upregulated during obesity and insulin resistance [62]. Recently, it was suggested that the role of PDK4 in insulin resistance was related to augmented MAMs formation, $\mathrm{Ca}^{2+}$ overload, and mitochondrial dysfunction [63]. To be more specific, PDK4 interacted with the IP3R1-Grp75-VDAC1 complex at MAMs. Obesity was found to be associated with increased PDK4 expression, enhanced MAMs formation, and insulin resistance, which could be ameliorated by PDK4 inhibition. Another MAMs-residing protein, promyelocytic leukemia (PML), is also likely to regulate insulin sensitivity by participating in $\mathrm{Ca}^{2+}$ homeostasis. Promyelocytic leukemia (PML) is a tumor suppressor that modulates apoptosis. PML is primarily enriched in a specific subnuclear structure called the PML nuclear body, while extranuclear PML is enriched at MAMs in the form of high-molecular-weight complexes with IP3R, Akt, and PP2A [64]. It was suggested that PML was crucial for Akt- and PP2A-dependent regulation of IP3R-mediated $\mathrm{Ca}^{2+}$ release from the ER [64]. In conclusion, $\mathrm{Ca}^{2+}$ dysregulation at MAMs is another mechanism accounting for insulin resistance [65]. Restorations of ER-mitochondria contacts and $\mathrm{Ca}^{2+}$ homeostasis represent a potential approach to correcting hepatic and muscle insulin resistance.

\subsection{Metabolic Homeostasis and Insulin Resistance}

Metabolic flexibility refers to the ability of organisms and cells to efficiently adapt metabolism to altered nutrient availability and requirements by substrate sensing, trafficking, storage, and utilization [66]. When organisms are unable to adapt their metabolism to energetic alterations, disrupted homeostasis results in metabolic disturbance, such as obesity, insulin resistance, and type 2 diabetes [47]. The mitochondria and ER are both organelles sensitive to cellular energetic levels. Mitochondria are involved in ATP synthesis, autophagy, and apoptosis, while the ER plays a key role in protein synthesis, folding, sorting, and delivery.

There are multiple systems of quality control to ensure proper amounts and function of mitochondria, including mitochondrial biogenesis, mitochondrial fusion/fission, and mitophagy [67]. Upon starvation, Drp1 is phosphorylated, causing mitochondrial fusion, while mitochondria tend to maintain a fragmented state in nutrient excess [68]. In addition, acetylation of mitochondrial proteins and adjustment of mitochondria content are also key processes that guarantee metabolic flexibility $[69,70]$. Similarly, the ER triggers unfolded protein response (UPR) in the face of overload of glucose and fatty acid in order to restore metabolic homeostasis.

Nutritional state has been suggested to affect the amount and function of MAMs. PP2A is a serine/threonine phosphatase involved in energy metabolism. A significant reduction of MAMs amount was observed in the liver of fed mice compared with fasted mice, likely through the PP-PP2A pathway [51]. Moreover, the effect of nutritional state on MAMs was impaired in the liver of $o b / o b$ and CypD-KO mice, implying that disruption of MAMs might result in mitochondrial dysfunction and hepatic insulin resistance [51]. As an MAMs-locating protein that forms a complex with Akt and PP2A [64], PML also participates in energy balance by regulating PPARs [71], FOXO1 [72], and AMPK [73]. Evidence showed that PML-KO mice exhibited augmented fatty acid metabolism, aberrant glucose metabolism, and insulin resistance in the skeletal muscle [73]. In addition, the activation of Akt was abolished with PML ablation, therefore causing AMPK activation [73].

Collectively, the research findings presented above support the close relationship between impaired MAMs functions and insulin resistance (Figure 2). Specifically, disrupted MAMs integrity and altered MAMs juxtaposition contribute to insulin resistance through impaired $\mathrm{Ca}^{2+}$ exchange, altered lipid metabolism, and dysregulated insulin signaling molecules. In addition, impaired $\mathrm{Ca}^{2+}$ homeostasis seems to be a crucial link between MAMs and the impaired signaling pathway, as modified apoptotic level, mitochondrial dysfunction, and excessive ERS are all associated with $\mathrm{Ca}^{2+}$ imbalance and insulin resistance. 


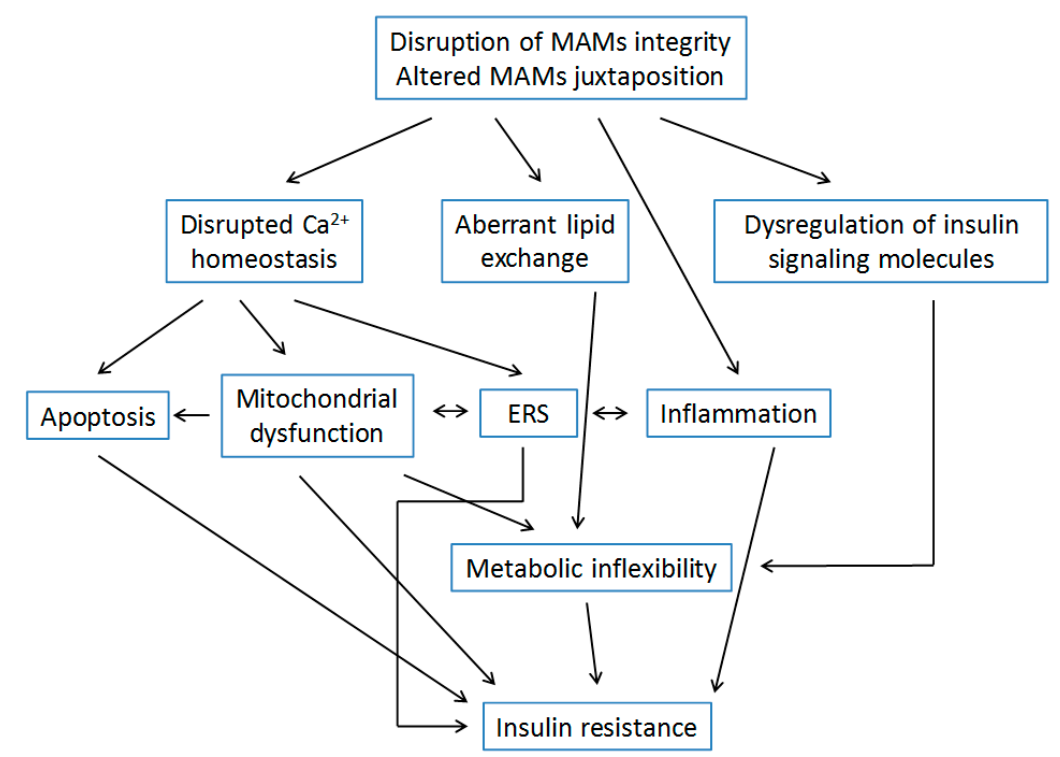

Figure 2. Schematic mechanisms by which alterations of the structure and functions of MAMs may contribute to insulin resistance.

\section{MAMs, Insulin Resistance, and Exercise Intervention}

It is well established that exercise deficiency contributes to the occurrence of obesity and type 2 diabetes (T2DM), which are both associated with systemic insulin resistance. On the other hand, solid evidence suggests that exercise plays an important role in the prevention and treatment of the above pathological conditions. Insulin sensitivity can be acutely improved by even a single bout of exercise. For example, acute one-legged exercise caused more rapid insulin-stimulated glucose uptake and glycogen synthase activity [74]. Similarly, a single day of moderate cycling exercise resulted in improved insulin sensitivity the next day [75]. Since both aerobic and resistance exercise could acutely improve insulin action, it is vital that insulin-resistant people exercise regularly to acquire continued health benefits [76]. Chronic aerobic exercise significantly lowered insulin concentration and the HOMA index in T2DM women [77]. Similarly, aerobic exercise training was proved effective in reducing fasting insulin level and the HOMA index in overweight/obese children/adolescents [78].

\subsection{Exercise Intervention for Mitochondrial Quality Control and Insulin Resistance}

For a long time, mitochondria were mainly considered as the site for energy production and oxidative phosphorylation. Now, we know that mitochondria are also indispensable for various cellular processes, including ROS production, autophagy, aging, apoptosis, redox signaling, etc. Dysfunction of mitochondria is associated with several diseases, including obesity, metabolic syndrome, cancer, and neurodegenerative diseases. Compromised mitochondrial activity and decreased mitochondrial content were reported in the skeletal muscle of adults with insulin resistance [79]. Decreased mitochondrial oxidative capacity causes over-accumulation of lipids, which, in turn, exacerbates insulin resistance.

Mitophagy is a key process that influences mitochondrial quality, and is vital for maintaining insulin sensitivity. Studies investigating the role of mitophagy in insulin resistance have emerged over the last few years. As a mitophagy mediator, PTEN-induced putative kinase 1 (PINK1) expression was decreased under insulin resistance conditions. However, evidence from other studies showed that ablation of autophagy-related gene 7 (Atg7) or FUN14 domain-containing 1 (Fundc1) alleviated insulin resistance $[80,81]$. Therefore, it seems that a delicate level of mitophagy is required for maintaining insulin sensitivity.

Exercise training poses positive effects on insulin sensitivity and glycemic control through mitochondrial adaptation. Training volume is a key factor in exercise-induced mitochondrial 
biogenesis [82]. Recently, researchers suggested that training intensity might be another important factor to stimulate mitochondrial function. For example, high-intensity interval training (HIIT) was superior to continuous aerobic training in improving insulin sensitivity and glucose tolerance and increasing muscle mitochondrial content [83]. In addition to training volume and intensity, exercise modality is another factor taken into consideration when prescribing an exercise regimen to overcome insulin resistance. For many years, strength training was known to influence muscle adaptation by increasing myofibrillar units [84]. However, recent studies suggested that resistance training could also elicit increased mitochondrial respiration to a similar extent to aerobic training in both lean subjects and T2DM patients $[85,86]$. Therefore, the combination of endurance and resistance training is considered a more effective behavioral intervention for T2DM according to the ADA/ACSM guidelines for diabetes. Like in muscle, exercise could also induce similar effects on insulin resistance and mitochondrial adaptation in the brain. For example, aerobic exercise improved HFD-induced mitochondrial dysfunction by ameliorating insulin resistance [87].

\subsection{Exercise Intervention for ERS and Insulin Resistance}

The ER is the main site in which folding and post-translational modifications of proteins occur. Under stressful conditions, the homeostasis of the ER is disrupted, and misfolded or unfolded proteins accumulate in the ER [88]. What happens next is that the UPR is triggered to restore ER function through three signal transducers, including activating transcription factor 6 (ATF6), inositol-requiring enzyme $1 \alpha$ (IRE1 $\alpha)$, and protein kinase R-like ER protein kinase (PERK). When the UPR is not efficient enough to restore ER function, pathological changes are observed, including inflammation, insulin resistance, apoptosis, etc. [89]. Disruption of ER homeostasis is considered one of the prominent features of obesity, insulin resistance, and T2DM. Studies showed that aberrant activation of ERS is related to impaired insulin sensitivity. For example, animal models of insulin resistance, including HFD-induced obese mice and $o b / o b$ mice, showed increased PERK phosphorylation [90].

Insulin resistance is usually associated with low-grade inflammation. Several studies have provided an intriguing link between inflammation, ERS, and insulin resistance. In particular, c-jun $\mathrm{N}$-terminal kinase (JNK) and I kappa $\beta$ kinase (IKK $\beta)$ are associated with ERS and act as inhibitors of insulin signaling, based on the fact that activation of IKK $\beta$ aggravates ERS and impaired insulin signaling $[90,91]$. Exercise training is believed to exert beneficial effects to correct ERS in most cases. For example, swimming training decreased pro-inflammatory molecules, such as JNK and $\mathrm{NF}-\mathrm{KB}$, reduced ERS, and improved insulin pathway in the adipose tissue and the liver of diet-induced obese rats [92]. Interestingly, concomitant intervention of HFD and exercise seemed to exert different effects on ERS and UPR compared to exercise intervention on the already obese rats [92,93]. When HFD and treadmill exercise began at the same time and both lasted for six weeks, exercise aggravated the UPR that was triggered by the HFD [93]. A possible explanation is that exercise induces adaptive changes to prepare for further potential challenges. It has been shown that aerobic exercise inhibited the activation of IKK $\beta$ and NF- $K B$ and improved insulin resistance dependent on IL- 6 and IL-10 in the hypothalamus [94]. In addition, exercise intensity seems to impact the effect of exercise intervention on ERS and insulin resistance. HIIT proved superior to low-intensity exercise in improving glycemic control, ERS, and glucagon-like peptide-1 (GLP-1) in T2DM adolescents [95]. Grp78, as the master regulator of the UPR, plays a vital role in modulating ERS. Under stressful events, ATF6, IRE1 $\alpha$, and PERK dissociate from Grp78 and are thus activated [96]. It is generally agreed that Grp78 is upregulated in obesity and insulin resistance, concomitant with increase of its targets, ATF6, IRE1 $\alpha$, and PERK $[95,97]$. However, the effect of exercise on Grp78 expression has not reached consensus. Some studies showed that exercise-induced improvement of insulin resistance was accompanied by an increase in serum Grp78 [95]. Moreover, HIIT seemed to induce a larger increase in Grp78 and better improvement in insulin sensitivity compared to low-intensity exercise in T2DM adolescents [95]. However, in other studies, supervised exercise training decreased the expression of Grp78 in both 
subcutaneous adipose tissue and plasma [97]. Therefore, the regulatory role of exercise for Grp78 and ERS is complex, and requires further investigations.

\subsection{The Effect of Exercise Intervention on MAMs and Insulin Resistance}

Studies investigating the impact of exercise intervention on MAMs have just emerged over the last few years. We now know that REDD1 (regulated in development and DNA damage responses 1)-mediated downregulation of protein synthesis following aerobic exercise was accompanied by a decrease in ER-mitochondria interaction [98]. In addition, swim training significantly lowered mitochondrial cholesterol level and enhanced Caveolin-1 expression in ALS mice, both of which were markers of MAMs [99]. However, the exact role of MAMs in cell adaptation to exercise stress is still unclear. Nevertheless, much evidence supported that exercise-induced alleviation of insulin resistance was achieved partly through MAMs components, and these findings will be reviewed in the following sections.

\subsubsection{Exercise, $\mathrm{Ca}^{2+}$ Homeostasis, and Insulin Resistance}

Intracellular $\mathrm{Ca}^{2+}$ dynamics affect a variety of cellular functions, such as cell proliferation and differentiation, gene expressions, cellular signaling, etc. Studies demonstrate that $\mathrm{Ca}^{2+}$ transients and $\mathrm{Ca}^{2+}$ signaling are influenced by both acute and chronic exercises. For example, acute exhaustive exercise profoundly influenced $\mathrm{Ca}^{2+}$ signaling in lymphocytes [100]. Similarly, as an important signaling protein for glucose uptake following exercise, CaMKII was increased immediately after both acute aerobic and resistance exercise and returned to baseline after $3 \mathrm{~h}$ in the skeletal muscle of rats [101]. Three-week voluntary exercise also improved intracellular $\mathrm{Ca}^{2+}$ signaling in lymphocytes, and $\mathrm{Ca}^{2+}$-regulating genes such as IP3R2 and MCU were downregulated as adaptive changes [102].

$\mathrm{Ca}^{2+}$ regulation is one of the main functions of MAMs, and disruption of intracellular $\mathrm{Ca}^{2+}$ homeostasis is closely associated with insulin resistance. For example, HFD induced cardiac $\mathrm{Ca}^{2+}$ disturbance, insulin resistance, and compromised SERCA and RYR expressions, which were markedly improved by six-week treadmill exercise [103]. The alteration of $\mathrm{Ca}^{2+}$ homeostasis during insulin resistance is also related to fatty acid metabolism. To be more specific, fatty acid synthase (FAS) activity is increased in the skeletal muscle during diet-induced insulin resistance. The enhanced FAS activity facilitates synthesis of PE at the SR to maintain SERCA activity, which causes decreased cytosolic $\mathrm{Ca}^{2+}$, depressed $\mathrm{Ca}^{2+}$ - and AMPK-dependent pathways, and muscle insulin resistance [104]. As the complex located at MAMs is in charge of $\mathrm{Ca}^{2+}$ transfer, the expression and function of IP3R-Grp75-VDAC1 are also affected by exercise. For example, the mRNA expression of IP3R2 was decreased in splenic lymphocytes by voluntary exercise, which was accompanied by improved intracellular $\mathrm{Ca}^{2+}$ signaling [102]. Grp75 is a family member of HSP70, and is actively involved in exercise-induced regulation of heat shock protein defense. The combination of exercise training and dietary intervention increased Grp75 in the skeletal muscle of individuals with impaired glucose tolerance [105]. The Grp75 mRNA level in a rat brain was also enhanced by exercise training [106]. However, the above studies only focused on the role of Grp75 as a heat stress protein, not as a $\mathrm{Ca}^{2+}$ signaling regulator. Therefore, further input is required to investigate the effect of exercise training on $\mathrm{Ca}^{2+}$ regulation related to MAMs.

\subsubsection{Exercise, MAMs Components, and Insulin Resistance}

As a crucial tethering protein at MAMs, Mfn2 is actively involved in insulin resistance. Mfn2 in rat cardiac muscle was downregulated by HFD, and was upregulated by exercise training [103]. At the same time, lower mitochondrial ROS level, higher mitochondrial membrane potential, and attenuated insulin resistance were observed in HFD rats following exercise intervention, which confirmed the role of Mfn2 in exercise-induced improvement in insulin sensitivity [103]. In some cases, even though Mfn2 level was not changed in response to diabetes, the ratio of Mfn2 to Drp1 was decreased and was prevented by exercise [107]. Therefore, the balance between mitochondrial biogenesis and 
mitochondrial fission is shifted towards excessive fission under diabetic conditions, and could be partially corrected by exercise training.

Insulin resistance is associated with altered mitochondrial structure and impaired mitochondrial function. The dysfunctional mitochondria need to be eliminated by the mitophagic process [108]. During mitophagy, ER and mitochondria are detached from each other, promoting mitochondrial degradation. In the above process, PINK1 and Parkin mediate ubiquitination of an OMM protein such as Mfn2, and destroy the contacts between the mitochondria and ER [109]. Exercise training could induce autophagy in the normal skeletal muscle and lead to improvement in obesity-induced impairment of mitophagy $[110,111]$. Based on the above evidence, it is reasonable to propose that exercise training may relieve insulin resistance by upregulating Parkin to degrade Mfn2 and promoting detachment of the ER and mitochondria.

\subsubsection{Exercise, MAMs-Located Proteins, and Insulin Resistance}

As an insulin-activated serine threonine kinase, Akt is actively involved in insulin- and exercise-induced glucose uptake. Even though some earlier studies showed that in vitro muscle contraction did not enhance Akt activity, it is generally agreed base on most evidence that the expression and activity of Akt are altered in response to exercise. In addition, the impaired Akt level in insulin resistance could be partially or fully reversed by exercise training. For example, eight-week swimming exercise profoundly enhanced the Akt and p-Akt ${ }^{\mathrm{Ser} 473}$ levels in the quadriceps muscle of HFD mice [112]. Similarly, six-week resistance training evidently increased p-Akt and GSK-3 $\beta$ in the skeletal muscle of diabetic rats [113]. In addition, voluntary exercise could improve insulin resistance in the liver of diabetic rats by inhibiting the iNOS level as well as the S-nitrosylation of Akt [114]. The impact of exercise on Akt modification is closely related to TRB3, a mammalian homolog of Drosophila tribbles that is actively involved in cell growth, cell differentiation, and metabolic processes [115]. Insulin resistance induced by HFD, obesity, and T2DM caused an increase in TRB3 [116], while exercise disrupted the interaction between TRB3 and Akt, therefore releasing Akt for further phosphorylation and activation [117].

Compared to the well-established role of mTORC2 in resistance-exercise-induced muscle hypertrophy [118], the physiological role of mTORC1 in response to exercise is less known. Studies have demonstrated that besides Akt, mTORC2 is also involved in insulin-induced glucose uptake. Moreover, Rictor KO mice exhibited impaired muscle glucose uptake during treadmill exercise, suggesting that mTORC2 was an essential component of exercise-induced glucose uptake [119]. In addition, HFD caused systemic insulin resistance and decreased muscle mTORC2 while combined interventions of dietary control and exercise training rescued the downregulated mTORC2 [120].

\section{Conclusions}

Since first observed in the 1950s, MAMs have been the focus of many scientific research groups. The significance of MAMs in insulin resistance has started to be elucidated, and growing evidence supports the involvement of this apposition in maintaining insulin sensitivity by mediating $\mathrm{Ca}^{2+}$ regulation, insulin signaling, and metabolic homeostasis. In addition, MAMs modulation is considered as a good target for potential pharmacological therapies and exercise interventions. However, even though ER-mitochondria tethers and MAMs-located molecules have been studied regarding their roles in regulating insulin sensitivity, the involvement of MAMs in glucose homeostasis is still not clear. Moreover, some conflicting results were drawn due to the different disease models (obesity, type 2 diabetes, insulin resistance, NAFLD) and intervention methods (pharmacologic vs. genetic manipulation) used. Therefore, the role of ER-mitochondria contacts in the pathogenesis of insulin resistance is still to be explored. Furthermore, the impact of exercise intervention on MAMs modification remains an open question. Much input is required to understand whether and how alterations of MAMs' structure and functions are involved in insulin sensitivity enhancement by different types of exercise. 
Author Contributions: Conceptualization, Y.S. and S.D.; Writing-Original Draft Preparation, Y.S.; Writing-Review and Editing, S.D.; Funding Acquisition, Y.S. and S.D. Both authors have read and agreed to the published version of the manuscript.

Funding: This work was supported by grants from National Natural Science Foundation of China (Grant 31600967, 31671241). This work was also supported by the Fundamental Research Funds for the Central Universities, and by the Key Laboratory Construction Project of Adolescent Health Assessment and Exercise Intervention of the Ministry of Education (Grant 11000-30190-513300/006).

Conflicts of Interest: The authors declare no conflict of interest.

\section{Abbreviations}

\begin{tabular}{|c|c|}
\hline ER & Endoplasmic reticulum \\
\hline MAMs & Mitochondria-associated ER membranes \\
\hline NAFLD & nonalcoholic fatty liver disease \\
\hline PACS-2 & phosphofurin acidic cluster sorting protein 2 \\
\hline Mfn2 & mitofusin 2 \\
\hline IP3R & inositol 1, 4, 5-triphosphate receptor \\
\hline VAPB & vesicle-associated membrane-protein-associated protein B \\
\hline PTPIP51 & protein tyrosine phosphatase-interacting protein 51 \\
\hline CNX & calnexin \\
\hline SERCA & sarco/ER Ca ${ }^{2+}$ ATPase \\
\hline Sig1R & sigma-1 \\
\hline Ero1 $\alpha$ & endoplasmic reticulum oxidoreductin- $1 \alpha$ \\
\hline PSS & phosphatidylserine synthase \\
\hline CypD & cyclophilin D \\
\hline mTORC2 & mammalian TOR complex 2 \\
\hline OMM & outer mitochondrial membrane \\
\hline TpMs & trichoplein/mitostatin \\
\hline mPTP & mitochondrial permeability transition pore \\
\hline PE & phosphatidylethanolamine \\
\hline PC & phosphatidylcholine \\
\hline PMCA & plasma membrane $\mathrm{Ca}^{2+}$ ATPases \\
\hline RyR & ryanodine receptor \\
\hline MCU & mitochondrial $\mathrm{Ca}^{2+}$ uniporter \\
\hline PC2 & polycystin 2 \\
\hline PLA & proximity ligation assay \\
\hline HFD & high-fat diet \\
\hline Giamp5 & GTPase of immune-associated protein 5 \\
\hline IRSs & insulin receptor substrates \\
\hline sGC/PKG & soluble guanylate cyclase/protein kinase G \\
\hline ERS & ER stress \\
\hline PDK4 & pyruvate dehydrogenase kinase 4 \\
\hline PML & promyelocytic leukemia \\
\hline UPR & unfolded protein response \\
\hline T2DM & type 2 diabetes \\
\hline PINK1 & PTEN-induced putative kinase 1 \\
\hline Atg7 & autophagy related gene 7 \\
\hline Fundc1 & FUN14 domain-containing 1 \\
\hline HIIT & high-intensity interval training \\
\hline ATF6 & activating transcription factor 6 \\
\hline IRE1 $\alpha$ & inositol-requiring enzyme $1 \alpha$ \\
\hline PERK & protein kinase R-like ER protein kinase \\
\hline JNK & c-jun N-terminal kinase \\
\hline $\mathrm{IKK} \beta$ & I kappa $\beta$ kinase \\
\hline GLP-1 & glucagon-like peptide-1 \\
\hline REDD1 & regulated in development and DNA damage responses 1 \\
\hline FAS & fatty acid synthase \\
\hline
\end{tabular}




\section{References}

1. Lopez-Crisosto, C.; Bravo-Sagua, R.; Rodriguez-Pena, M.; Mera, C.; Castro, P.F.; Quest, A.F.; Rothermel, B.A.; Cifuentes, M.; Lavandero, S. ER-to-mitochondria miscommunication and metabolic diseases. Biochim. Biophys. Acta 2015, 1852 Pt A, 2096-2105. [CrossRef]

2. Costello, J.L.; Passmore, J.B.; Islinger, M.; Schrader, M. Multi-localized Proteins: The Peroxisome-Mitochondria Connection. Subcell. Biochem. 2018, 89, 383-415. [PubMed]

3. Benador, I.Y.; Veliova, M.; Liesa, M.; Shirihai, O.S. Mitochondria Bound to Lipid Droplets: Where Mitochondrial Dynamics Regulate Lipid Storage and Utilization. Cell Metab. 2019, 29, 827-835. [CrossRef] [PubMed]

4. Giorgi, C.; Missiroli, S.; Patergnani, S.; Duszynski, J.; Wieckowski, M.R.; Pinton, P. Mitochondria-associated membranes: Composition, molecular mechanisms, and physiopathological implications. Antioxid. Redox. Signal. 2015, 22, 995-1019. [CrossRef] [PubMed]

5. Sasi, U.; Ganapathy, S.; Palayyan, S.R.; Gopal, R.K. Mitochondria Associated Membranes (MAMs): Emerging Drug Targets for Diabetes. Curr. Med. Chem. 2020, 27, 3362-3385. [CrossRef] [PubMed]

6. Yang, M.; Li, C.; Sun, L. Mitochondria-Associated Membranes (MAMs): A Novel Therapeutic Target for Treating Metabolic Syndrome. Curr. Med. Chem. 2020. [CrossRef] [PubMed]

7. Wang, J.; He, W.; Tsai, P.J.; Chen, P.H.; Ye, M.; Guo, J.; Su, Z. Mutual interaction between endoplasmic reticulum and mitochondria in nonalcoholic fatty liver disease. Lipids Health Dis. 2020, 19, 72. [CrossRef]

8. Danese, A.; Patergnani, S.; Bonora, M.; Wieckowski, M.R.; Previati, M.; Giorgi, C.; Pinton, P. Calcium regulates cell death in cancer: Roles of the mitochondria and mitochondria-associated membranes (MAMs). Biochim. Biophys. Acta Bioenergy 2017, 1858, 615-627. [CrossRef]

9. Delprat, B.; Maurice, T.; Delettre, C. Wolfram syndrome: MAMs' connection? Cell Death Dis. 2018, 9, 364. [CrossRef]

10. Rodriguez-Arribas, M.; Yakhine-Diop, S.; Pedro, J.; Gomez-Suaga, P.; Gomez-Sanchez, R.; Martinez-Chacon, G.; Fuentes, J.M.; Gonzalez-Polo, R.A.; Niso-Santano, M. Mitochondria-Associated Membranes (MAMs): Overview and Its Role in Parkinson's Disease. Mol. Neurobiol. 2017, 54, 6287-6303. [CrossRef]

11. Li, C.; Li, L.; Yang, M.; Zeng, L.; Sun, L. PACS-2: A key regulator of mitochondria-associated membranes (MAMs). Pharmacol. Res. 2020, 160, 105080. [CrossRef] [PubMed]

12. Sebastian, D.; Hernandez-Alvarez, M.I.; Segales, J.; Sorianello, E.; Munoz, J.P.; Sala, D.; Waget, A.; Liesa, M.; Paz, J.C.; Gopalacharyulu, P.; et al. Mitofusin 2 (Mfn2) links mitochondrial and endoplasmic reticulum function with insulin signaling and is essential for normal glucose homeostasis. Proc. Natl. Acad. Sci. USA 2012, 109, 5523-5528. [CrossRef] [PubMed]

13. Iwasawa, R.; Mahul-Mellier, A.L.; Datler, C.; Pazarentzos, E.; Grimm, S. Fis1 and Bap31 bridge the mitochondria-ER interface to establish a platform for apoptosis induction. EMBO J. 2011, 30, 556-568. [CrossRef] [PubMed]

14. Gomez-Suaga, P.; Paillusson, S.; Stoica, R.; Noble, W.; Hanger, D.P.; Miller, C. The ER-Mitochondria Tethering Complex VAPB-PTPIP51 Regulates Autophagy. Curr. Biol. 2017, 27, 371-385. [CrossRef]

15. Di Mattia, T.; Wilhelm, L.P.; Ikhlef, S.; Wendling, C.; Spehner, D.; Nomine, Y.; Giordano, F.; Mathelin, C.; Drin, G.; Tomasetto, C.; et al. Identification of MOSPD2, a novel scaffold for endoplasmic reticulum membrane contact sites. EMBO Rep. 2018, 19, 7. [CrossRef]

16. Myhill, N.; Lynes, E.M.; Nanji, J.A.; Blagoveshchenskaya, A.D.; Fei, H.; Carmine, S.K.; Cooper, T.J.; Thomas, G.; Simmen, T. The subcellular distribution of calnexin is mediated by PACS-2. Mol. Biol. Cell. 2008, 19, 2777-2788. [CrossRef]

17. Weng, T.Y.; Tsai, S.A.; Su, T.P. Roles of sigma-1 receptors on mitochondrial functions relevant to neurodegenerative diseases. J. Biomed. Sci. 2017, 24, 74. [CrossRef]

18. Gilady, S.Y.; Bui, M.; Lynes, E.M.; Benson, M.D.; Watts, R.; Vance, J.E.; Simmen, T. Ero1alpha requires oxidizing and normoxic conditions to localize to the mitochondria-associated membrane (MAM). Cell Stress Chaperones 2010, 15, 619-629. [CrossRef]

19. Lewin, T.M.; Kim, J.H.; Granger, D.A.; Vance, J.E.; Coleman, R.A. Acyl-CoA synthetase isoforms 1, 4, and 5 are present in different subcellular membranes in rat liver and can be inhibited independently. J. Biol. Chem. 2001, 276, 24674-24679. [CrossRef] 
20. Stone, S.J.; Vance, J.E. Phosphatidylserine synthase-1 and -2 are localized to mitochondria-associated membranes. J. Boil. Chem. 2000, 275, 34534-34540. [CrossRef]

21. Yang, M.; Li, C.; Yang, S.; Xiao, Y.; Xiong, X.; Chen, W.; Zhao, H.; Zhang, Q.; Han, Y.; Sun, L. Mitochondria-Associated ER Membranes-The Origin Site of Autophagy. Front. Cell Dev. Biol. 2020, 8, 595. [CrossRef] [PubMed]

22. Paillard, M.; Tubbs, E.; Thiebaut, P.A.; Gomez, L.; Fauconnier, J.; Da, S.C.; Teixeira, G.; Mewton, N.; Belaidi, E.; Durand, A.; et al. Depressing mitochondria-reticulum interactions protects cardiomyocytes from lethal hypoxia-reoxygenation injury. Circulation 2013, 128, 1555-1565. [CrossRef] [PubMed]

23. Tubbs, E.; Theurey, P.; Vial, G.; Bendridi, N.; Bravard, A.; Chauvin, M.A.; Ji-Cao, J.; Zoulim, F.; Bartosch, B.; Ovize, M.; et al. Mitochondria-associated endoplasmic reticulum membrane (MAM) integrity is required for insulin signaling and is implicated in hepatic insulin resistance. Diabetes 2014, 63, 3279-3294. [CrossRef] [PubMed]

24. Csordas, G.; Renken, C.; Varnai, P.; Walter, L.; Weaver, D.; Buttle, K.F.; Balla, T.; Mannella, C.A.; Hajnoczky, G. Structural and functional features and significance of the physical linkage between ER and mitochondria. J. Cell Biol. 2006, 174, 915-921. [CrossRef]

25. Rizzuto, R.; Pinton, P.; Carrington, W.; Fay, F.S.; Fogarty, K.E.; Lifshitz, L.M.; Tuft, R.A.; Pozzan, T. Close contacts with the endoplasmic reticulum as determinants of mitochondrial $\mathrm{Ca}^{2+}$ responses. Science 1998, 280, 1763-1766. [CrossRef]

26. Rossi, A.E.; Boncompagni, S.; Dirksen, R.T. Sarcoplasmic reticulum-mitochondrial symbiosis: Bidirectional signaling in skeletal muscle. Exerc. Sport Sci. Rev. 2009, 37, 29-35. [CrossRef]

27. Szabadkai, G.; Bianchi, K.; Varnai, P.; De Stefani, D.; Wieckowski, M.R.; Cavagna, D.; Nagy, A.I.; Balla, T.; Rizzuto, R. Chaperone-mediated coupling of endoplasmic reticulum and mitochondrial $\mathrm{Ca}^{2+}$ channels. J. Cell Biol. 2006, 175, 901-911. [CrossRef]

28. Helle, S.C.; Kanfer, G.; Kolar, K.; Lang, A.; Michel, A.H.; Kornmann, B. Organization and function of membrane contact sites. Biochim. Biophys. Acta 2013, 1833, 2526-2541. [CrossRef]

29. de Brito, O.M.; Scorrano, L. Mitofusin 2 tethers endoplasmic reticulum to mitochondria. Nature 2008, 456, 605-610. [CrossRef]

30. Cerqua, C.; Anesti, V.; Pyakurel, A.; Liu, D.; Naon, D.; Wiche, G.; Baffa, R.; Dimmer, K.S.; Scorrano, L. Trichoplein/mitostatin regulates endoplasmic reticulum-mitochondria juxtaposition. EMBO Rep. 2010, 11, 854-860. [CrossRef]

31. Sugiura, A.; Nagashima, S.; Tokuyama, T.; Amo, T.; Matsuki, Y.; Ishido, S.; Kudo, Y.; McBride, H.M.; Fukuda, T.; Matsushita, N.; et al. Mitol regulates endoplasmic reticulum-mitochondria contacts via Mitofusin2. Mol. Cell 2013, 51, 20-34. [CrossRef] [PubMed]

32. Simmen, T.; Aslan, J.E.; Blagoveshchenskaya, A.D.; Thomas, L.; Wan, L.; Xiang, Y.; Feliciangeli, S.F.; Hung, C.H.; Crump, C.M.; Thomas, G. PACS-2 controls endoplasmic reticulum-mitochondria communication and Bid-mediated apoptosis. EMBO J. 2005, 24, 717-729. [CrossRef] [PubMed]

33. Betz, C.; Stracka, D.; Prescianotto-Baschong, C.; Frieden, M.; Demaurex, N.; Hall, M.N. Feature Article: mTOR complex 2-Akt signaling at mitochondria-associated endoplasmic reticulum membranes (MAM) regulates mitochondrial physiology. Proc. Natl. Acad. Sci. USA 2013, 110, 12526-12534. [CrossRef] [PubMed]

34. Vance, J.E. Molecular and cell biology of phosphatidylserine and phosphatidylethanolamine metabolism. Prog. Nucleic Acid. Res. Mol. Biol. 2003, 75, 69-111. [PubMed]

35. Hamasaki, M.; Furuta, N.; Matsuda, A.; Nezu, A.; Yamamoto, A.; Fujita, N.; Oomori, H.; Noda, T.; Haraguchi, T.; Hiraoka, Y.; et al. Autophagosomes form at ER-mitochondria contact sites. Nature 2013, 495, 389-393. [CrossRef] [PubMed]

36. Walter, L.; Hajnoczky, G. Mitochondria and endoplasmic reticulum: The lethal interorganelle cross-talk. J. Bioenergy Biomembr. 2005, 37, 191-206. [CrossRef]

37. Rizzuto, R.; De Stefani, D.; Raffaello, A.; Mammucari, C. Mitochondria as sensors and regulators of calcium signalling. Nat. Rev. Mol. Cell Biol. 2012, 13, 566-578. [CrossRef]

38. Clapham, D.E. Calcium signaling. Cell 2007, 131, 1047-1058. [CrossRef]

39. Xu, H.; Guan, N.; Ren, Y.L.; Wei, Q.J.; Tao, Y.H.; Yang, G.S.; Liu, X.Y.; Bu, D.F.; Zhang, Y.; Zhu, S.N. IP3R-Grp75-VDAC1-MCU calcium regulation axis antagonists protect podocytes from apoptosis and decrease proteinuria in an Adriamycin nephropathy rat model. BMC Nephrol. 2018, 19, 140. [CrossRef] 
40. Roderick, H.L.; Lechleiter, J.D.; Camacho, P. Cytosolic phosphorylation of calnexin controls intracellular $\mathrm{Ca}(2+)$ oscillations via an interaction with SERCA2b. J. Cell. Biol. 2000, 149, 1235-1248. [CrossRef]

41. Yu, S.; Zhang, L.; Liu, C.; Yang, J.; Zhang, J.; Huang, L. PACS2 is required for ox-LDL-induced endothelial cell apoptosis by regulating mitochondria-associated ER membrane formation and mitochondrial $\mathrm{Ca}(2+)$ elevation. Exp. Cell Res. 2019, 379, 191-202. [CrossRef] [PubMed]

42. Kuo, I.Y.; Brill, A.L.; Lemos, F.O.; Jiang, J.Y.; Falcone, J.L.; Kimmerling, E.P.; Cai, Y.; Dong, K.; Kaplan, D.L.; Wallace, D.P.; et al. Polycystin 2 regulates mitochondrial $\mathrm{Ca}(2+)$ signaling, bioenergetics, and dynamics through mitofusin 2. Sci. Signal. 2019, 12, 580. [CrossRef] [PubMed]

43. Filadi, R.; Greotti, E.; Turacchio, G.; Luini, A.; Pozzan, T.; Pizzo, P. Mitofusin 2 ablation increases endoplasmic reticulum-mitochondria coupling. Proc. Natl. Acad. Sci. USA 2015, 112, E2174-E2181. [CrossRef] [PubMed]

44. Gomez-Suaga, P.; Paillusson, S.; Miller, C. ER-mitochondria signaling regulates autophagy. Autophagy 2017, 13, 1250-1251. [CrossRef] [PubMed]

45. Di Meo, S.; Iossa, S.; Venditti, P. Skeletal muscle insulin resistance: Role of mitochondria and other ROS sources. J. Endocrinol. 2017, 233, R15-R42. [CrossRef]

46. Mannella, C.A.; Buttle, K.; Rath, B.K.; Marko, M. Electron microscopic tomography of rat-liver mitochondria and their interaction with the endoplasmic reticulum. BioFactors 1998, 8, 225-228. [CrossRef]

47. Theurey, P.; Rieusset, J. Mitochondria-Associated Membranes Response to Nutrient Availability and Role in Metabolic Diseases. Trends Endocrinol. Metab. 2017, 28, 32-45. [CrossRef]

48. Rieusset, J. Contribution of mitochondria and endoplasmic reticulum dysfunction in insulin resistance: Distinct or interrelated roles? Diabetes Metab. 2015, 41, 358-368. [CrossRef]

49. Arruda, A.P.; Pers, B.M.; Parlakgul, G.; Guney, E.; Inouye, K.; Hotamisligil, G.S. Chronic enrichment of hepatic endoplasmic reticulum-mitochondria contact leads to mitochondrial dysfunction in obesity. Nat. Med. 2014, 20, 1427-1435. [CrossRef]

50. Tubbs, E.; Chanon, S.; Robert, M.; Bendridi, N.; Bidaux, G.; Chauvin, M.A.; Ji-Cao, J.; Durand, C.; Gauvrit-Ramette, D.; Vidal, H.; et al. Disruption of Mitochondria-Associated Endoplasmic Reticulum Membrane (MAM) Integrity Contributes to Muscle Insulin Resistance in Mice and Humans. Diabetes 2018, 67, 636-650. [CrossRef]

51. Theurey, P.; Tubbs, E.; Vial, G.; Jacquemetton, J.; Bendridi, N.; Chauvin, M.A.; Alam, M.R.; Le Romancer, M.; Vidal, H.; Rieusset, J. Mitochondria-associated endoplasmic reticulum membranes allow adaptation of mitochondrial metabolism to glucose availability in the liver. J. Mol. Cell Biol. 2016, 8, 129-143. [CrossRef] [PubMed]

52. Gan, K.X.; Wang, C.; Chen, J.H.; Zhu, C.J.; Song, G.Y. Mitofusin-2 ameliorates high-fat diet-induced insulin resistance in liver of rats. World J. Gastroenterol. 2013, 19, 1572-1581. [CrossRef] [PubMed]

53. Schneeberger, M.; Dietrich, M.O.; Sebastian, D.; Imbernon, M.; Castano, C.; Garcia, A.; Esteban, Y.; Gonzalez-Franquesa, A.; Rodriguez, I.C.; Bortolozzi, A.; et al. Mitofusin 2 in POMC neurons connects ER stress with leptin resistance and energy imbalance. Cell 2013, 155, 172-187. [CrossRef] [PubMed]

54. Wang, C.H.; Chen, Y.F.; Wu, C.Y.; Wu, P.C.; Huang, Y.L.; Kao, C.H.; Lin, C.H.; Kao, L.S.; Tsai, T.F.; Wei, Y.H. Cisd 2 modulates the differentiation and functioning of adipocytes by regulating intracellular $\mathrm{Ca}^{2+}$ homeostasis. Hum. Mol. Genet. 2014, 23, 4770-4785. [CrossRef]

55. Destefano, M.A.; Jacinto, E. Regulation of insulin receptor substrate-1 by mTORC2 (mammalian target of rapamycin complex 2). Biochem. Soc. Trans. 2013, 41, 896-901. [CrossRef]

56. De Palma, C.; Falcone, S.; Pisoni, S.; Cipolat, S.; Panzeri, C.; Pambianco, S.; Pisconti, A.; Allevi, R.; Bassi, M.T.; Cossu, G.; et al. Nitric oxide inhibition of Drp1-mediated mitochondrial fission is critical for myogenic differentiation. Cell Death Differ. 2010, 17, 1684-1696. [CrossRef]

57. Nisoli, E.; Falcone, S.; Tonello, C.; Cozzi, V.; Palomba, L.; Fiorani, M.; Pisconti, A.; Brunelli, S.; Cardile, A.; Francolini, M.; et al. Mitochondrial biogenesis by NO yields functionally active mitochondria in mammals. Proc. Natl. Acad. Sci. USA 2004, 101, 16507-16512. [CrossRef]

58. Bassot, A.; Chauvin, M.A.; Bendridi, N.; Ji-Cao, J.; Vial, G.; Monnier, L.; Bartosch, B.; Alves, A.; Cottet-Rousselle, C.; Gouriou, Y.; et al. Regulation of Mitochondria-Associated Membranes (MAMs) by NO/sGC/PKG Participates in the Control of Hepatic Insulin Response. Cells 2019, 8, 1319. [CrossRef]

59. Lim, J.H.; Lee, H.J.; Ho, J.M.; Song, J. Coupling mitochondrial dysfunction to endoplasmic reticulum stress response: A molecular mechanism leading to hepatic insulin resistance. Cell Signal. 2009, 21, 169-177. [CrossRef] 
60. Fu, S.; Yang, L.; Li, P.; Hofmann, O.; Dicker, L.; Hide, W.; Lin, X.; Watkins, S.M.; Ivanov, A.R.; Hotamisligil, G.S. Aberrant lipid metabolism disrupts calcium homeostasis causing liver endoplasmic reticulum stress in obesity. Nature 2011, 473, 528-531. [CrossRef]

61. Szado, T.; Vanderheyden, V.; Parys, J.B.; De Smedt, H.; Rietdorf, K.; Kotelevets, L.; Chastre, E.; Khan, F.; Landegren, U.; Soderberg, O.; et al. Phosphorylation of inositol 1,4,5-trisphosphate receptors by protein kinase B/Akt inhibits $\mathrm{Ca}^{2+}$ release and apoptosis. Proc. Natl. Acad. Sci. USA 2008, 105, 2427-2432. [CrossRef] [PubMed]

62. Jeoung, N.H.; Harris, R.A. Pyruvate dehydrogenase kinase-4 deficiency lowers blood glucose and improves glucose tolerance in diet-induced obese mice. Am. J. Physiol. Endocrinol. Metab. 2008, 295, E46-E54. [CrossRef] [PubMed]

63. Thoudam, T.; Ha, C.M.; Leem, J.; Chanda, D.; Park, J.S.; Kim, H.J.; Jeon, J.H.; Choi, Y.K.; Liangpunsakul, S.; Huh, Y.H.; et al. PDK4 Augments ER-Mitochondria Contact to Dampen Skeletal Muscle Insulin Signaling during Obesity. Diabetes 2019, 68, 571-586. [CrossRef] [PubMed]

64. Giorgi, C.; Ito, K.; Lin, H.K.; Santangelo, C.; Wieckowski, M.R.; Lebiedzinska, M.; Bononi, A.; Bonora, M.; Duszynski, J.; Bernardi, R.; et al. PML regulates apoptosis at endoplasmic reticulum by modulating calcium release. Science 2010, 330, 1247-1251. [CrossRef] [PubMed]

65. Filadi, R.; Theurey, P.; Pizzo, P. The endoplasmic reticulum-mitochondria coupling in health and disease: Molecules, functions and significance. Cell Calcium. 2017, 62, 1-15. [CrossRef]

66. Smith, R.L.; Soeters, M.R.; Wust, R.; Houtkooper, R.H. Metabolic Flexibility as an Adaptation to Energy Resources and Requirements in Health and Disease. Endocr. Rev. 2018, 39, 489-517. [CrossRef]

67. Pickles, S.; Vigie, P.; Youle, R.J. Mitophagy and Quality Control Mechanisms in Mitochondrial Maintenance. Curr. Biol. 2018, 28, R170-R185. [CrossRef]

68. Gomes, L.C.; Di Benedetto, G.; Scorrano, L. During autophagy mitochondria elongate, are spared from degradation and sustain cell viability. Nat. Cell Biol. 2011, 13, 589-598. [CrossRef]

69. Ahn, B.H.; Kim, H.S.; Song, S.; Lee, I.H.; Liu, J.; Vassilopoulos, A.; Deng, C.X.; Finkel, T. A role for the mitochondrial deacetylase Sirt3 in regulating energy homeostasis. Proc. Natl. Acad. Sci. USA 2008, 105, 14447-14452. [CrossRef]

70. Jeninga, E.H.; Schoonjans, K.; Auwerx, J. Reversible acetylation of PGC-1: Connecting energy sensors and effectors to guarantee metabolic flexibility. Oncogene 2010, 29, 4617-4624. [CrossRef]

71. Kim, M.K.; Yang, S.; Lee, K.H.; Um, J.H.; Liu, M.; Kang, H.; Park, S.J.; Chung, J.H. Promyelocytic leukemia inhibits adipogenesis, and loss of promyelocytic leukemia results in fat accumulation in mice. Am. J. Physiol. Endocrinol. Metab. 2011, 301, E1130-E1142. [CrossRef] [PubMed]

72. Kitamura, Y.I.; Kitamura, T.; Kruse, J.P.; Raum, J.C.; Stein, R.; Gu, W.; Accili, D. FoxO1 protects against pancreatic beta cell failure through NeuroD and MafA induction. Cell Metab. 2005, 2, 153-163. [CrossRef] [PubMed]

73. Cheng, X.; Guo, S.; Liu, Y.; Chu, H.; Hakimi, P.; Berger, N.A.; Hanson, R.W.; Kao, H.Y. Ablation of promyelocytic leukemia protein (PML) re-patterns energy balance and protects mice from obesity induced by a Western diet. J. Biol. Chem. 2013, 288, 29746-29759. [CrossRef] [PubMed]

74. Wojtaszewski, J.F.P.; Hansen, B.F.; Gade, J.; Kiens, B.; Markuns, J.F.; Goodyear, L.J.; Richter, E.A. Insulin signaling and insulin sensitivity after exercise in human skeletal muscle. Diabetes 2000, 49, 325-331. [CrossRef]

75. Ding, C.; Chooi, Y.; Chan, Z.; Lo, J.; Choo, J.; Ding, B.; Leow, M.K.; Magkos, F. Dose-Dependent Effects of Exercise and Diet on Insulin Sensitivity and Secretion. Med. Sci. Sports Exerc. 2019, 51, 2109-2116. [CrossRef] [PubMed]

76. Colberg, S.R.; Sigal, R.J.; Fernhall, B.; Regensteiner, J.G.; Blissmer, B.J.; Rubin, R.R.; Chasan-Taber, L.; Albright, A.L.; Braun, B. Exercise and type 2 diabetes: The American College of Sports Medicine and the American Diabetes Association: Joint position statement. Diabetes Care 2010, 33, e147-e167. [CrossRef]

77. Motahari-Tabari, N.; Ahmad, S.M.; Shirzad-E-Ahoodashty, M.; Yousefi-Abdolmaleki, E.; Teimourzadeh, M. The effect of 8 weeks aerobic exercise on insulin resistance in type 2 diabetes: A randomized clinical trial. Glob. J. Health Sci. 2014, 7, 115-121. [CrossRef]

78. Marson, E.C.; Delevatti, R.S.; Prado, A.K.; Netto, N.; Kruel, L.F. Effects of aerobic, resistance, and combined exercise training on insulin resistance markers in overweight or obese children and adolescents: A systematic review and meta-analysis. Prev. Med. 2016, 93, 211-218. [CrossRef] 
79. Kelley, D.E.; He, J.; Menshikova, E.V.; Ritov, V.B. Dysfunction of mitochondria in human skeletal muscle in type 2 diabetes. Diabetes 2002, 51, 2944-2950. [CrossRef]

80. Scheele, C.; Nielsen, A.R.; Walden, T.B.; Sewell, D.A.; Fischer, C.P.; Brogan, R.J.; Petrovic, N.; Larsson, O.; Tesch, P.A.; Wennmalm, K.; et al. Altered regulation of the PINK1 locus: A link between type 2 diabetes and neurodegeneration? FASEB J. 2007, 21, 3653-3665. [CrossRef]

81. Kim, K.H.; Jeong, Y.T.; Oh, H.; Kim, S.H.; Cho, J.M.; Kim, Y.N.; Kim, S.S.; Kim, D.H.; Hur, K.Y.; Kim, H.K.; et al. Autophagy deficiency leads to protection from obesity and insulin resistance by inducing Fgf21 as a mitokine. Nat. Med. 2013, 19, 83-92. [CrossRef] [PubMed]

82. Bishop, D.J.; Granata, C.; Eynon, N. Can we optimise the exercise training prescription to maximise improvements in mitochondria function and content? Biochim. Biophys. Acta 2014, 1840, 1266-1275. [CrossRef]

83. De Strijcker, D.; Lapauw, B.; Ouwens, D.M.; Van de Velde, D.; Hansen, D.; Petrovic, M.; Cuvelier, C.; Tonoli, C.; Calders, P. High intensity interval training is associated with greater impact on physical fitness, insulin sensitivity and muscle mitochondrial content in males with overweight/obesity, as opposed to continuous endurance training: A randomized controlled trial. J. Musculoskelet. Neuronal. Interact. 2018, 18, 215-226. [PubMed]

84. Di Meo, S.; Iossa, S.; Venditti, P. Improvement of obesity-linked skeletal muscle insulin resistance by strength and endurance training. J. Endocrinol. 2017, 234, R159-R181. [CrossRef] [PubMed]

85. Pesta, D.; Hoppel, F.; Macek, C.; Messner, H.; Faulhaber, M.; Kobel, C.; Parson, W.; Burtscher, M.; Schocke, M.; Gnaiger, E. Similar qualitative and quantitative changes of mitochondrial respiration following strength and endurance training in normoxia and hypoxia in sedentary humans. Am. J. Physiol. Regul. Integr. Comp. Physiol. 2011, 301, R1078-R1087. [CrossRef] [PubMed]

86. Sparks, L.M.; Johannsen, N.M.; Church, T.S.; Earnest, C.P.; Moonen-Kornips, E.; Moro, C.; Hesselink, M.K.; Smith, S.R.; Schrauwen, P. Nine months of combined training improves ex vivo skeletal muscle metabolism in individuals with type 2 diabetes. J. Clin. Endocrinol. Metab. 2013, 98, 1694-1702. [CrossRef]

87. Ruegsegger, G.N.; Vanderboom, P.M.; Dasari, S.; Klaus, K.A.; Kabiraj, P.; McCarthy, C.B.; Lucchinetti, C.F.; Nair, K.S. Exercise and metformin counteract altered mitochondrial function in the insulin-resistant brain. JCI Insight 2019, 4, 18. [CrossRef]

88. Zhang, K.; Kaufman, R.J. The unfolded protein response: A stress signaling pathway critical for health and disease. Neurology 2006, 66 (Suppl. 1), S102-S109. [CrossRef]

89. Szegezdi, E.; Fitzgerald, U.; Samali, A. Caspase-12 and ER-stress-mediated apoptosis: The story so far. Ann. N. Y. Acad. Sci. 2003, 1010, 186-194. [CrossRef]

90. Ozcan, U.; Cao, Q.; Yilmaz, E.; Lee, A.H.; Iwakoshi, N.N.; Ozdelen, E.; Tuncman, G.; Gorgun, C.; Glimcher, L.H.; Hotamisligil, G.S. Endoplasmic reticulum stress links obesity, insulin action, and type 2 diabetes. Science 2004, 306, 457-461. [CrossRef]

91. Zhang, X.; Zhang, G.; Zhang, H.; Karin, M.; Bai, H.; Cai, D. Hypothalamic IKKbeta/NF-kappaB and ER stress link overnutrition to energy imbalance and obesity. Cell 2008, 135, 61-73. [CrossRef] [PubMed]

92. Da, L.G.; Frederico, M.J.; Da, S.S.; Vitto, M.F.; Cesconetto, P.A.; de Pinho, R.A.; Pauli, J.R.; Silva, A.S.; Cintra, D.E.; Ropelle, E.R.; et al. Endurance exercise training ameliorates insulin resistance and reticulum stress in adipose and hepatic tissue in obese rats. Eur. J. Appl. Physiol. 2011, 111, 2015-2023.

93. Deldicque, L.; Cani, P.D.; Delzenne, N.M.; Baar, K.; Francaux, M. Endurance training in mice increases the unfolded protein response induced by a high-fat diet. J. Physiol. Biochem. 2013, 69, 215-225. [CrossRef] [PubMed]

94. Ropelle, E.R.; Flores, M.B.; Cintra, D.E.; Rocha, G.Z.; Pauli, J.R.; Morari, J.; de Souza, C.T.; Moraes, J.C.; Prada, P.O.; Guadagnini, D.; et al. IL-6 and IL-10 anti-inflammatory activity links exercise to hypothalamic insulin and leptin sensitivity through IKKbeta and ER stress inhibition. PLoS Biol. 2010, 8. [CrossRef]

95. Lee, S.S.; Yoo, J.H.; So, Y.S. Effect of the low- versus high-intensity exercise training on endoplasmic reticulum stress and GLP-1 in adolescents with type 2 diabetes mellitus. J. Phys. Ther. Sci. 2015, 27, 3063-3068. [CrossRef]

96. Wang, S.; Kaufman, R.J. The impact of the unfolded protein response on human disease. J. Cell Biol. 2012, 197, 857-867. [CrossRef] 
97. Khadir, A.; Kavalakatt, S.; Abubaker, J.; Cherian, P.; Madhu, D.; Al-Khairi, I.; Abu-Farha, M.; Warsame, S.; Elkum, N.; Dehbi, M.; et al. Physical exercise alleviates ER stress in obese humans through reduction in the expression and release of GRP78 chaperone. Metabolism 2016, 65, 1409-1420. [CrossRef]

98. Merle, A.; Jollet, M.; Britto, F.A.; Goustard, B.; Bendridi, N.; Rieusset, J.; Ollendorff, V.; Favier, F.B. Endurance exercise decreases protein synthesis and ER-mitochondria contacts in mouse skeletal muscle. J. Appl. Physiol. 2019, 127, 1297-1306. [CrossRef]

99. Flis, D.J.; Dzik, K.; Kaczor, J.J.; Halon-Golabek, M.; Antosiewicz, J.; Wieckowski, M.R.; Ziolkowski, W. Swim Training Modulates Skeletal Muscle Energy Metabolism, Oxidative Stress, and Mitochondrial Cholesterol Content in Amyotrophic Lateral Sclerosis Mice. Oxid. Med. Cell. Longev. 2018, 2018, 5940748. [CrossRef]

100. Mooren, F.C.; Lechtermann, A.; Fromme, A.; Thorwesten, L.; Volker, K. Alterations in intracellular calcium signaling of lymphocytes after exhaustive exercise. Med. Sci. Sports Exerc. 2001, 33, 242-248. [CrossRef]

101. Cheng, K.K.Y.; Lam, K.S.L.; Wang, B.; Xu, A. Signaling mechanisms underlying the insulin-sensitizing effects of adiponectin. Best Pract. Res. Clin. Endocrinol. Metab. 2014, 28, 3-13. [CrossRef] [PubMed]

102. Liu, R.; Fan, W.; Kruger, K.; Xiao, Y.U.; Pilat, C.; Seimetz, M.; Ringseis, R.; Baumgart-Vogt, E.; Eder, K.; Weissmann, N.; et al. Exercise Affects T-Cell Function by Modifying Intracellular Calcium Homeostasis. Med. Sci. Sports Exerc. 2017, 49, 29-39. [CrossRef] [PubMed]

103. Palee, S.; Minta, W.; Mantor, D.; Sutham, W.; Jaiwongkam, T.; Kerdphoo, S.; Pratchayasakul, W.; Chattipakorn, S.C.; Chattipakorn, N. Combination of exercise and calorie restriction exerts greater efficacy on cardioprotection than monotherapy in obese-insulin resistant rats through the improvement of cardiac calcium regulation. Metabolism 2019, 94, 77-87. [CrossRef] [PubMed]

104. Funai, K.; Lodhi, I.J.; Spears, L.D.; Yin, L.; Song, H.; Klein, S.; Semenkovich, C.F. Skeletal Muscle Phospholipid Metabolism Regulates Insulin Sensitivity and Contractile Function. Diabetes 2016, 65, 358-370. [CrossRef] [PubMed]

105. Venojarvi, M.; Aunola, S.; Puhke, R.; Marniemi, J.; Hamalainen, H.; Halonen, J.P.; Lindstrom, J.; Rastas, M.; Hallsten, K.; Nuutila, P.; et al. Exercise training with dietary counselling increases mitochondrial chaperone expression in middle-aged subjects with impaired glucose tolerance. BMC Endocr. Disord. 2008, 8, 3. [CrossRef] [PubMed]

106. Lappalainen, Z.; Lappalainen, J.; Oksala, N.K.; Laaksonen, D.E.; Khanna, S.; Sen, C.K.; Atalay, M. Exercise training and experimental diabetes modulate heat shock protein response in brain. Scand. J. Med. Sci. Sports 2010, 20, 83-89. [CrossRef] [PubMed]

107. Veeranki, S.; Givvimani, S.; Kundu, S.; Metreveli, N.; Pushpakumar, S.; Tyagi, S.C. Moderate intensity exercise prevents diabetic cardiomyopathy associated contractile dysfunction through restoration of mitochondrial function and connexin 43 levels in db/db mice. J. Mol. Cell. Cardiol. 2016, 92, 163-173. [CrossRef]

108. Heo, J.W.; No, M.H.; Park, D.H.; Kang, J.H.; Seo, D.Y.; Han, J.; Neufer, P.D.; Kwak, H.B. Effects of exercise on obesity-induced mitochondrial dysfunction in skeletal muscle. Korean J. Physiol. Pharmacol. 2017, 21, 567-577. [CrossRef]

109. McLelland, G.L.; Goiran, T.; Yi, W.; Dorval, G.; Chen, C.X.; Lauinger, N.D.; Krahn, A.I.; Valimehr, S.; Rakovic, A.; Rouiller, I.; et al. Mfn2 ubiquitination by PINK1/parkin gates the p97-dependent release of ER from mitochondria to drive mitophagy. eLife 2018, 7, e32866. [CrossRef]

110. Greene, N.P.; Lee, D.E.; Brown, J.L.; Rosa, M.E.; Brown, L.A.; Perry, R.A.; Henry, J.N.; Washington, T.A. Mitochondrial quality control, promoted by PGC-1alpha, is dysregulated by Western diet-induced obesity and partially restored by moderate physical activity in mice. Physiol. Rep. 2015, 3, e12470. [CrossRef]

111. Yan, Z.; Lira, V.A.; Greene, N.P. Exercise training-induced regulation of mitochondrial quality. Exerc. Sport Sci. Rev. 2012, 40, 159-164. [CrossRef] [PubMed]

112. Qi, J.; Yang, B.; Ren, C.; Fu, J.; Zhang, J. Swimming Exercise Alleviated Insulin Resistance by Regulating Tripartite Motif Family Protein 72 Expression and AKT Signal Pathway in Sprague-Dawley Rats Fed with High-Fat Diet. J. Diabetes Res. 2016, 2016, 1564386. [CrossRef]

113. Kido, K.; Ato, S.; Yokokawa, T.; Sato, K.; Fujita, S. Resistance training recovers attenuated APPL1 expression and improves insulin-induced Akt signal activation in skeletal muscle of type 2 diabetic rats. Am. J. Physiol. Metab. 2018, 314, E564-E571. [CrossRef] [PubMed] 
114. Tsuzuki, T.; Shinozaki, S.; Nakamoto, H.; Kaneki, M.; Goto, S.; Shimokado, K.; Kobayashi, H.; Naito, H. Voluntary Exercise Can Ameliorate Insulin Resistance by Reducing iNOS-Mediated S-Nitrosylation of Akt in the Liver in Obese Rats. PLoS ONE 2015, 10, e0132029. [CrossRef] [PubMed]

115. Du, K.; Herzig, S.; Kulkarni, R.N.; Montminy, M. TRB3: A tribbles homolog that inhibits Akt/PKB activation by insulin in liver. Science 2003, 300, 1574-1577. [CrossRef]

116. Koh, H.J.; Toyoda, T.; Didesch, M.M.; Lee, M.Y.; Sleeman, M.W.; Kulkarni, R.N.; Musi, N.; Hirshman, M.F.; Goodyear, L.J. Tribbles 3 mediates endoplasmic reticulum stress-induced insulin resistance in skeletal muscle. Nat. Commun. 2013, 4, 1871. [CrossRef] [PubMed]

117. Marinho, R.; Mekary, R.A.; Munoz, V.R.; Gomes, R.J.; Pauli, J.R.; de Moura, L.P. Regulation of hepatic TRB3/Akt interaction induced by physical exercise and its effect on the hepatic glucose production in an insulin resistance state. Diabetol. Metab. Syndr. 2015, 7, 67. [CrossRef]

118. Marcotte, G.R.; West, D.W.; Baar, K. The molecular basis for load-induced skeletal muscle hypertrophy. Calcif. Tissue Int. 2015, 96, 196-210. [CrossRef]

119. Kleinert, M.; Parker, B.L.; Fritzen, A.M.; Knudsen, J.R.; Jensen, T.E.; Kjobsted, R.; Sylow, L.; Ruegg, M.; James, D.E.; Richter, E.A. Mammalian target of rapamycin complex 2 regulates muscle glucose uptake during exercise in mice. J. Physiol. 2017, 595, 4845-4855. [CrossRef]

120. Bae, J.Y.; Shin, K.O.; Woo, J.; Woo, S.H.; Jang, K.S.; Lee, Y.H.; Kang, S. Exercise and dietary change ameliorate high fat diet induced obesity and insulin resistance via mTOR signaling pathway. J. Exerc. Nutr. Biochem. 2016, 20, 28-33. [CrossRef]

Publisher's Note: MDPI stays neutral with regard to jurisdictional claims in published maps and institutional affiliations.

(C) 2020 by the authors. Licensee MDPI, Basel, Switzerland. This article is an open access article distributed under the terms and conditions of the Creative Commons Attribution (CC BY) license (http://creativecommons.org/licenses/by/4.0/). 